\title{
Estructura de tamaños de las comunidades microbianas en sistemas acuáticos salinos del alto Guadalquivir
}

\author{
Andrea Galotti*, Francisco Jiménez-Gómez y Francisco Guerrero
}

Departamento de Biología Animal, Biología Vegetal y Ecología. Universidad de Jaén. Campus Las Lagunillas, s/n. Edf. B3. 23071-Jaén. España.

* Autor responsable de la correspondencia: agalotti@ujaen.es

\section{RESUMEN}

Estructura de tamaños de las comunidades microbianas en sistemas acuáticos salinos del alto Guadalquivir

El presente trabajo aborda el análisis de la estructura de tamaños de la comunidad microbiana de tres ecosistemas acuáticos salinos de la provincia de Jaén (laguna Honda y salinas de San Carlos y de Los Vélez), situados en la cuenca alta del río Guadalquivir. Los tres ecosistemas objeto de estudio presentaron claras diferencias en las condiciones ambientales, con unas concentraciones medias de sales muy oscilantes y que estuvieron comprendidas entre los $14 \mathrm{~g} / \mathrm{l}$ de la laguna Honda y los 156 g/l registrados en la salina Los Vélez. Una combinación de técnicas de citometría de flujo y microscopía de epifluorescencia ha permitido la rápida caracterización de la estructura de tamaños de la comunidad microbiana de estos sistemas. Los resultados obtenidos describen unas comunidades caracterizadas por unos espectros de biovolumen alejados de la linealidad y con una discontinuidad en la transición entre bacterias y fitoplancton. Es de destacar, además, la gran diferencia existente entre los espectros de la laguna Honda y los de las salinas, con una discontinuidad mucho más patente en estos últimos, de acuerdo a la esperada menor complejidad de la comunidad desarrollada en estos sistemas más extremos.

Palabras clave: Ecosistemas hipersalinos, bacterias, picoplancton, citometría de flujo, estructura de tamaños.

\begin{abstract}
Size structure of microbial communities in saline aquatic systems of Alto Guadalquivir

In this paper we analyse the size structure of the planktonic microbial community of three saline aquatic ecosystems of the Jaén Province (Honda Lake, San Carlos and Los Vélez saltern), located in the Alto Guadalquivir basin. The three ecosystems studied presented clear differences in environmental conditions with strongly oscillating mean salinity levels ranging between $14 \mathrm{~g} / \mathrm{l}$ from Honda Lake and $156 \mathrm{~g} / \mathrm{l}$ in Los Vélez. Combining flow cytometric and epifluorescence techniques allowed for a rapid characterisation of the size structure of microbial communities of these systems. The results show a non linear size biomass spectrum characterized by one discontinuity in the transition between bacteria and phytoplankton size ranges. Moreover, this discontinuity was broader and more evident in the most saline systems, according to the expected lower complexity of these more extreme ecosystems.
\end{abstract}

Keywords: Hypersaline ecosystems, bacteria, picoplankton, flow cytometry, biomass size spectrum.

\section{INTRODUCCIÓN}

Los ecosistemas acuáticos hipersalinos poseen singulares cualidades para ser objetos de estudios ecológicos, no habiéndoseles, sin embargo, prestado demasiada atención en el ámbito de la limnología. En comparación con otros sistemas acuáticos epicontinentales, caracterizados por una gran diversidad de especies, por una mayor heterogeneidad de los hábitats y complejidad de las relaciones tróficas, los sistemas salinos presentan una marcada reducción de la diversidad debido a su alto nivel de estrés (Margalef, 1968; Dussart, 1977; Ayadi et al., 2004). La baja biomasa que suele caracterizar a estos ecosistemas viene dada en gran medida por el predomi- 
nio de microalgas y bacterias (Margalef, 1983; Sorokin, 1999), presentando unas cadenas tróficas más simplificadas y dominadas por comunidades microbianas poco diversas (Sorokin, 1999; Antón et al., 2000).

No obstante, estos sistemas hipersalinos, aparentemente menos complejos en el funcionamiento y organización de sus comunidades que el resto de ecosistemas acuáticos, constituyen un magnífico banco de pruebas para el contraste y desarrollo de aproximaciones metodológicas novedosas. Entre estas herramientas, el análisis de las distribuciones de tamaños de las comunidades planctónicas se ha revelado como una de las más prometedoras cuando han sido aplicadas al estudio de ecosistemas marinos y epicontinentales de gran tamaño (Sheldon et al., 1972; Platt \& Denman, 1978; Rodríguez \& Mullin, 1986; Sprules, 1988; Rodríguez et al., 1998).

Uno de los grandes problemas de este enfoque radica en la carencia de suficientes datos empíricos con los que validar sus postulados. En este sentido, los estudios sobre métodos de determinación de la estructura de tamaños de comunidades planctónicas presentan un gran valor en sí mismos (Rodríguez \& Li, 1994). El amplio rango a cubrir y la gran variedad funcional de los grupos constituyentes requieren a menudo el uso de una gran gama de técnicas para tal fin. La citometría de flujo (FCM en adelante) ocupa un lugar destacado entre las técnicas más recientemente llegadas al campo de la ecología. Esta técnica permite la caracterización de las propiedades ópticas de miles de partículas (células en este caso) en pocos minutos de forma individualizada, lo cual permite conectar propiedades individuales con la ecología de las comunidades fitoplanctónicas (Platt, 1989; Li, 1994; Rodríguez \& Li, 1994). Adicionalmente, con esta técnica se puede determinar el tamaño de las células de una suspensión acuosa mediante la dispersión frontal de luz de las mismas (FSC), siguiendo las oportunas calibraciones con muestras naturales y con esferas de látex de tamaños conocidos (Cucci \& Sieracki, 2001). No obstante, las medidas de tamaños de las partículas del tamaño de las bacterias requieren del uso de otras técnicas, como es el uso del análisis de imagen conectado a la mi- croscopía de epifluorescencia (p.ej., Sieracki et al., 1985; Jiménez-Gómez et al., 1994) y su aplicación al estudio de las estructuras de tamaños de comunidades pelágicas ha sido ampliamente desarrollada (Rodríguez \& Li, 1994). En el presente trabajo se usa por primera vez en sistemas hipersalinos la conjunción del análisis de imagen conectado a microscopía de epifluorescencia y la citometría de flujo para la obtención de espectros de tamaños de las comunidades microbianas.

Los modelos surgidos de los estudios de espectros de tamaños generalmente predicen una tendencia regular de distribución de la biomasa en cada clase de tamaño (Platt, 1985). Esta tendencia podría verse alterada por fenómenos ecológicos como la depredación, la cascada trófica o las proliferaciones fitoplanctónicas, que ocasionarían momentáneamente la pérdida de esa regularidad (Sprules, 1988).

La cuestión ecológica que planteamos aquí es si esa estructura irregular del espectro de tamaños guarda alguna relación con el grado de estrés del ecosistema estudiado, y si es gradual de acuerdo a la intensidad de la variable provocadora del estrés, la salinidad en este caso. Para tratar de responderla se ha analizado la estructura promediada del espectro de tamaños de la comunidad microbiana en tres cuerpos de agua de la cuenca alta del río Guadalquivir con diferentes salinidades, una laguna atalasohalina (laguna Honda) y dos salinas de interior en explotación (salina de Los Vélez y San Carlos).

\section{ÁREA DE ESTUDIO}

La comarca del Alto Guadalquivir se localiza al nordeste de Andalucía (España), englobando la casi totalidad de la provincia de Jaén y la parte más oriental de la provincia de Córdoba. Dentro de esta comarca se localizan una gran cantidad de ecosistemas salinos, caracterizados fundamentalmente por la presencia de arcillas y margas triásicas del Keuper que engloban olistolitos diversos (calcáreos y yesíferos), o por arcillas miocénicas (Langhiense superior) con bloques de dolomías triásicas entremezclados (olistolitos), que otorgan ese carácter salino a estos sistemas. 
La laguna Honda se encuentra situada al sudoeste de la provincia de Jaén, en el valle del río Guadalquivir (coordenadas geográficas UTM: 30SVG992619) a 460 metros sobre el nivel del mar. Las salinas de Los Vélez y San Carlos están situadas igualmente en la mitad occidental de la provincia de Jaén, a una altura de 480 y 380 m.s.n.m. (UTM: 30SVG2784 y 30SVG4193, respectivamente). Ambas salinas se encontraban en explotación comercial en el momento del estudio.

\section{MATERIAL Y MÉTODOS}

Para la realización de este trabajo se llevaron a cabo una serie de muestreos intensivos en los tres sistemas estudiados. En la laguna Honda las muestras fueron recogidas durante ocho semanas entre el 27 de febrero de 2002 y el 1 de mayo del mismo año. En las salinas Los Vélez y San Carlos, los muestreos fueron llevados a cabo entre los días 9 y 11 de julio de 2002. Los muestreos en la laguna Honda se realizaron en la zona de mayor profundidad, a $50 \mathrm{~cm}$ de la superficie. En la salina San Carlos el punto de muestro se situó en la zona de alimentación de la salina (arroyo) por ofrecer valores de salinidad intermedios en relación a los demás sistemas estudiados. Finalmente, la recogida de muestras en la salina Los Vélez se llevó a cabo en tres calentadores con una esperable concentración creciente de sales.

En todos los casos se llevaron a cabo medidas in situ de $\mathrm{pH}$ y temperatura. Las muestras para el análisis de total de sólidos disueltos y clorofila fueron depositadas en viales de polietileno de $200 \mathrm{ml}$ y guardadas en frio hasta su posterior tratamiento en el laboratorio. Las medidas de TSD (Totales de Sólidos Disueltos) se realizaron por pesaje del material retenido tras la evaporación de $100 \mathrm{ml}$ de muestra de agua filtrada (filtro Whatman GF/C) en una estufa de aire seco durante 48 horas a $104{ }^{\circ} \mathrm{C}$. Las concentraciones de clorofila fueron determinadas mediante métodos fluorimétricos (UNESCO, 1994) tras la filtración de $100 \mathrm{ml}$ de muestra en filtros Whatmann GF/C y su extracción en acetona $90 \%$ durante 24 horas a $4{ }^{\circ} \mathrm{C}$ y obscuridad.

Las muestras para el análisis de FCM y EPM fueron recogidas en criotubos $(3.5 \mathrm{ml}) \mathrm{y}$ botes de vidrio inerte $(20 \mathrm{ml})$ respectivamente, fijadas con glutaraldehido a $1 \%$ (c.f.), y guardadas a $4{ }^{\circ} \mathrm{C}$ y en oscuridad hasta su inmediato análisis en laboratorio.

El análisis de la abundancia y biomasa del pico y nanoplancton se llevó a cabo mediante la técnica de citometría de flujo especialmente adaptada a la salinidad de los sistemas estudiados. El equipo utilizado ha sido un EPICSElite de COULTER Co ajustado a una amplificación logarítmica de los detectores, flujo de $87 \mu \mathrm{l} /$ minuto y umbral de detección para el sensor de las clorofilas situado en PMT: 148.

La medida del tamaño celular individual se realizó a partir de las señales de dispersión frontal de luz (FSC), para lo cual se realizó la calibración de dicha señal utilizando conjuntamente fluoroesferas de látex de tamaño conocido (Flowcheck, $10 \mu \mathrm{m}$; Flowset, 3.6 $\mu \mathrm{m}$ y Yellowgreen $0.98 \mu \mathrm{m})$ y de muestras de plancton filtradas por mallas de diferentes tamaños (5 y $2 \mu \mathrm{m})$.

Las medidas de abundancia y biovolumen de bacterias se realizaron mediante un equipo de análisis de imagen de alta resolución provisto de una cámara fotométrica CCD Sensys con una resolución de $1317 \times 1035$ pixels conectado a un microscopio de epifluorescencia Leica DMLB. Las bacterias fueron teñidas con DAPI (concentración final de $0.01 \mu \mathrm{g} / \mathrm{ml}$ ) y retenidas en filtros Nuclepore Black de $0.2 \mu \mathrm{m}$ de poro, siguiendo el procedimiento de Porter \& Feig (1980). Mediante la cámara de alta resolución, eran fotografiados 10 campos aleatorios a $1000 \times\left(2500 \mu \mathrm{m}^{2}\right)$ y procesados a través del software de libre uso NIH-Image. Como criterio de recuento se estableció el rechazo de aquellas partículas menores a 3 píxeles (teniendo en cuenta que la calibración de tal equipo es de 17.19 píxel/ $\mu \mathrm{m}$ ). Las medidas obtenidas a partir de cada especimen fueron el área y la longitud a fin de calcular el valor del volumen celular: $V=8.5(A)^{2.5}(P)^{-2}$, de acuerdo a la expresión facilitada en el manual de uso del sistema de análisis de imagen Quantimet500 , donde $V$ es el volumen celular, $A$ el área y $P$ el perímetro convexo. 


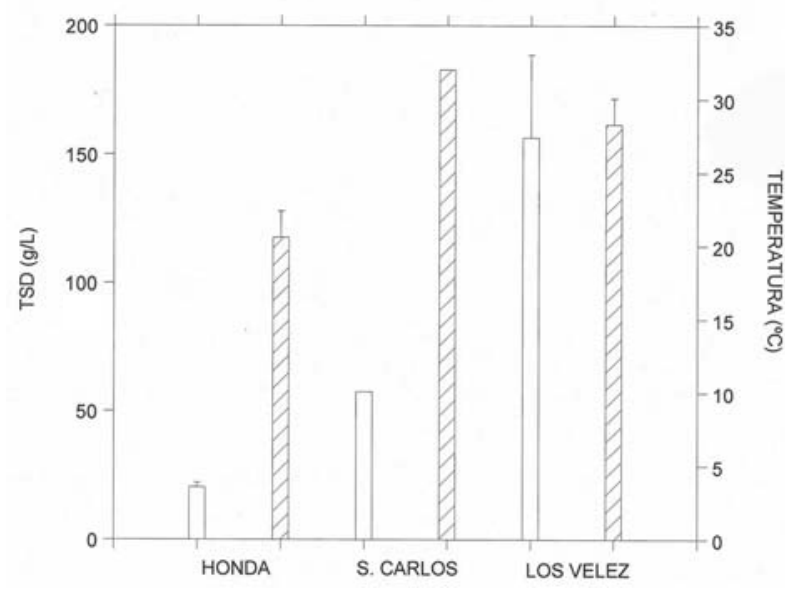

Figura 1. Valores medios del total de sólidos en disolución (TSD, barra clara) y de temperatura (barra rayada) de los sistemas estudiados durante el periodo de muestreo. Laguna Honda $n=7$, San Carlos $n=1$, Los Vélez $n=3$. Mean values of the total dissolved solids (TSD, open bar) and temperature (hatched bar) of the studied systems during the sampling period. Honda Lake $n=7$, San Carlos $n=1$, Los Vélez $n=3$.

\section{RESULTADOS Y DISCUSIÓN}

En la figura 1 se presentan los valores medios de salinidad (TSD) y temperatura en los tres sistemas durante el periodo de estudio. Estos valores muestran la diferente concentración de sólidos disueltos de los tres ecosistemas, con valores para la laguna Honda comprendidos entre $14 \mathrm{y}$ $23 \mathrm{~g} / \mathrm{l}$, que estarían muy por debajo de los más de $300 \mathrm{~g} / \mathrm{l}$ registrados por Guerrero \& Castro (1997) en periodos de sequía, y superiores para las salinas de San Carlos y Los Vélez, donde se alcanzan valores de 57 y $156 \mathrm{~g} / \mathrm{l}$, respectivamente. Estos valores encuadran, durante el periodo de estudio, a la laguna Honda como un sistema hipomesohalino y a las dos salinas como sistemas hipersalinos (Hammer, 1978).

El pH fue indicador de condiciones ligeramente alcalinas en las salinas, estando siempre comprendido entre 7.20 y 8.05 en todos los análisis efectuados. Por el contrario en la laguna Honda los valores de $\mathrm{pH}$ fueron extraordinariamente constantes, denotando una fuerte reserva alcalina y estando en todos los casos comprendidos entre 8.31 y 8.58 .

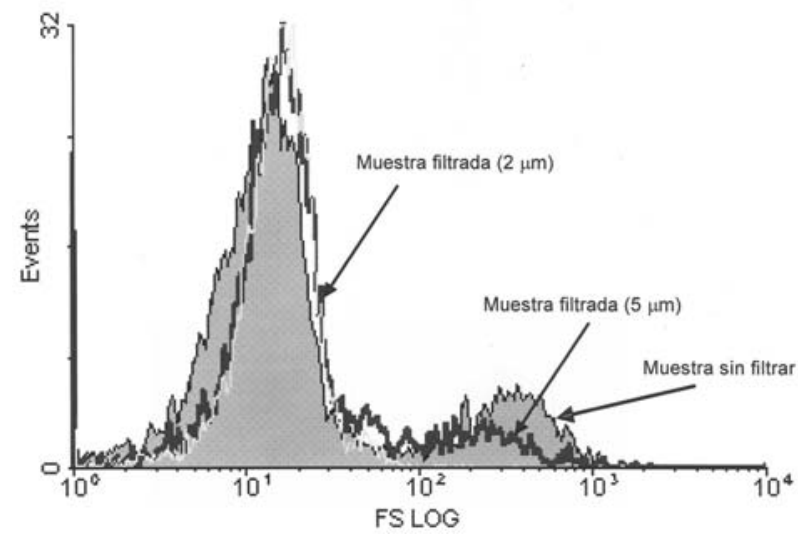

Figura 2. Representación monoparamétrica del valor de FSC correspondiente a cada una de las filtraciones realizadas y a la muestra sin filtrar (laguna Honda). Monoparametric representation of the FSC value of each filtered sample and the unfiltered one (Honda Lake).

En la figura 2 podemos ver el efecto que las diferentes filtraciones tuvieron sobre las poblaciones presentes en la muestra. Los canales que presentaron una reducción del $50 \%$ de los efectivos fueron tomados como indicativos del tamaño de malla. La representación conjunta de los datos de dispersión de luz de las esferas de calibración y de las filtraciones de fitoplancton (Fig. 3) ha permitido realizar la conversión de las señales de dispersión de luz (FSC) en medidas de volumen celular, según la expresión:

$$
D E E=0.028 * F S C+0.85
$$

La recta de calibración obtenida es válida para las condiciones de adquisición aplicadas en los análisis y para el equipo en particular usado en los mismos. Se puede apreciar la gran variabilidad de esta expresión comparándola con la obtenida por Reul et al. (2002) para un equipo FacScan de Becton Dickinson ( $\log B v=-1.78+$ $0.0055 * F S C$ ) y trabajando con el mismo conjunto de esferas de calibración.

Como un estimador de la biomasa fitoplanctónica se realizaron medidas rutinarias de la clorofila-a en cada uno de los sistemas. En el caso de la laguna Honda en todo el periodo de estudio los valores fueron extraordinariamen- 


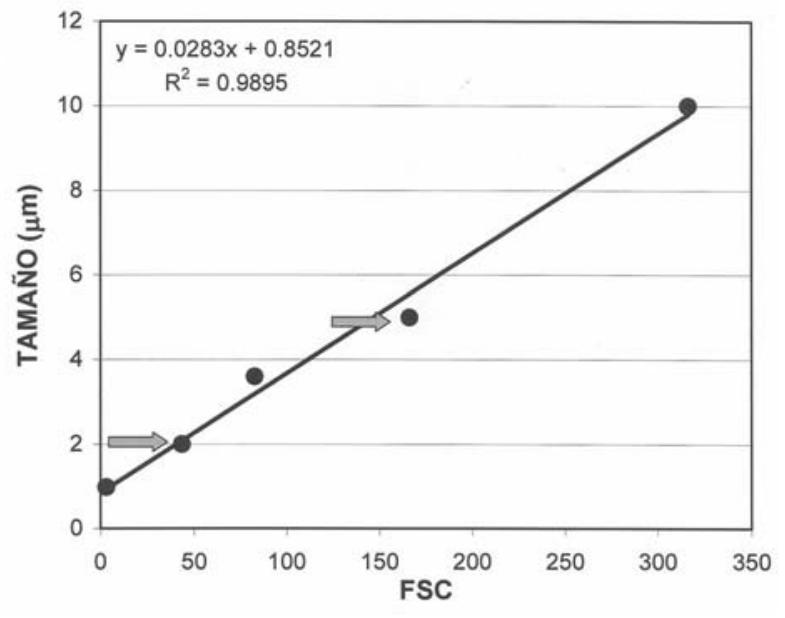

Figura 3. Relación entre los valores medios de los canales de dispersión frontal de luz (FSC) y de los tamaños de las partículas (DEE) para el conjunto de bolas de calibración y para las muestras fraccionadas procedentes de la laguna Honda (puntos señalados por flechas). Relationship between the frontal light scattering channel and the size of the particles (DEE) corresponding to the calibration beads and the fractionated samples from Honda lake (dots pointed by arrows).

te bajos, inferiores a $1.0 \mu \mathrm{g} / \mathrm{l}$. Sin embargo, las salinas presentaron concentraciones mayores, con $2.6 \mu \mathrm{g} / \mathrm{l}$ en la salina los Vélez y $2.7 \mu \mathrm{g} / \mathrm{l}$ en San Carlos (Tabla 1).

El análisis de la comunidad bacteriana puso de manifiesto la existencia de mayores densidades de bacterias en la laguna Honda, en torno a $3.5 \cdot 10^{6}$ bacterias $/ \mathrm{ml}$, que en las salinas, donde no superaron las $5.0 \cdot 10^{5}$ bacterias $/ \mathrm{ml}$. Habría que buscar la explicación a esta aparente paradoja en la posible existencia de vías alternativas de entrada de materia orgánica a la comunidad bacteriana de la laguna (macrófitos, material detrítico en suspensión, etc.) frente al ambiente extremo de las salinas. De acuerdo con
Wetzel \& Sondergaard (1998), la mayor parte de la producción bacteriana en lagos someros está asociada a las superficies, ya sean de macrófitos, sedimentos o rocas.

La aplicación de una técnica directa como es el análisis con microscopía de epifluorescencia permitió, además, la observación de una gran diferencia en la morfología de las bacterias de los sistemas estudiados. Las preparaciones procedentes de la laguna Honda presentaron una mayor homogeneidad de la comunidad, la mayoría con aspecto de cocos y bacilos, de un tamaño celular medio menor al apreciado en los otros sistemas. Por el contrario, las preparaciones de las salinas San Carlos y Los Vélez presentaron formas más complejas y diversas.

Las distribuciones de abundancia relativa de bacterias por clase de tamaños (Fig. 4) permiten apreciar, en primer lugar, el amplio rango de tamaños abarcado (11 órdenes de magnitud en una escala de octavas) y en segundo lugar, el gran tamaño medio de las bacterias de estos ecosistemas; con valores de 0.68, 0.72 y $0.98 \mu \mathrm{m}$ de DEE (Diámetro Esférico Equivalente) para las bacterias de la salina de Los Vélez, la laguna Honda y la salina San Carlos, respectivamente. Los valores más frecuentes encontrados en la bibliografía para bacterias marinas están comprendidos entre 0.02 (Lee \& Fuhrman, 1987) у $0.47 \mu \mathrm{m}^{3}$ (Gast \& Gocke, 1988). Para sistemas de agua dulce los datos apuntan a una dispersión semejante en el rango de volúmenes bacterianos, por ejemplo Cole et al. (1993), trabajando en 20 lagos Norteamericanos, publican valores comprendidos entre 0.01 y $0.2 \mu \mathrm{m}^{3}$. Sin embargo los valores medios en estos sistemas dulceacuícolas fueron ligeramente superiores a los

Tabla 1. Valores promediados de clorofila y biovolumen de bacterias, pico y nanoplancton en los tres sistemas estudiados. Averaged chlorophyll values and bacterial, pico, and nanoplanktonic biovolume in the three analysed ecosystems.

\begin{tabular}{cccccccccc}
\hline & \multicolumn{3}{c}{ LAGUNA HONDA } & \multicolumn{2}{c}{ S. LOS VÉLEZ } & \multicolumn{2}{c}{ S. SAN CARLOS } \\
\hline & promedio & $\boldsymbol{n}$ & error estándar & promedio & $\boldsymbol{n}$ & error estándar & promedio & $\boldsymbol{n}$ error estándar \\
\hline Clorofila $(\boldsymbol{\mu} \mathbf{g} / \mathbf{L})$ & 0.474 & 6 & 0.079 & 2.668 & 3 & 1.54 & 2.711 & 1 & - \\
Bv bacteriano $\left(\boldsymbol{\mu \mathbf { m } ^ { 3 }} / \mathbf{m l}\right)$ & $7.7 \cdot 10^{5}$ & 4 & $3.1 \cdot 10^{5}$ & $2.9 \cdot 10^{5}$ & 2 & - & $3.0 \cdot 10^{5}$ & 2 & - \\
Bv picoplancton $\left(\boldsymbol{\mu m}^{\mathbf{3}} / \mathbf{m l}\right)$ & $4.36 \cdot 10^{3}$ & 5 & $2.4 \cdot 10^{3}$ & - & - & - & - & - & - \\
Bv nanoplancton $\left(\boldsymbol{\mu m}^{3} / \mathbf{m l}\right)$ & $2.4 \cdot 10^{4}$ & 5 & $4.4 \cdot 10^{3}$ & $8.9 \cdot 10^{2}$ & 3 & $6.1 \cdot 10^{2}$ & $2.0 \cdot 10^{2}$ & 1 & - \\
\hline
\end{tabular}




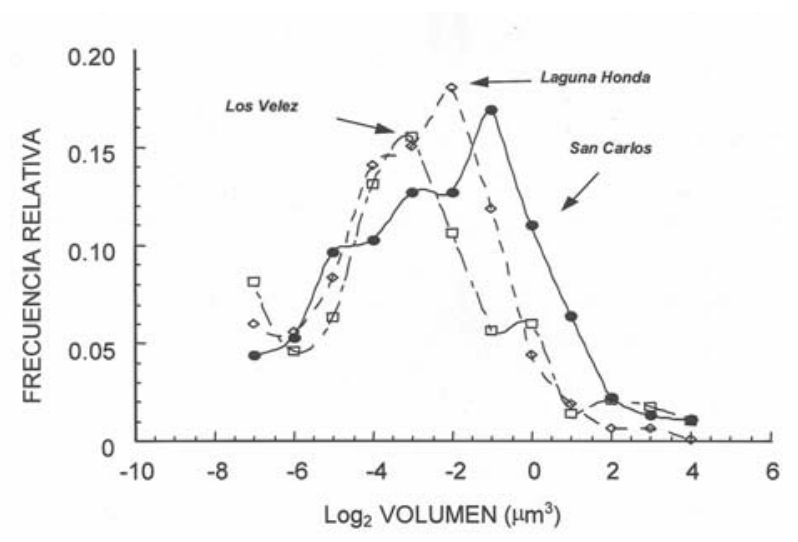

Figura 4. Frecuencia relativa de abundancia media bacteriana distribuida en clases logarítmicas de volumen $\left(\log _{2}\right)$ en los tres sistemas estudiados. Relative frequency of the average bacterial abundance over the volume log classes $\left(\log _{2}\right)$ in the three studied ecosystems.

encontrados en ambientes marinos. Así, Bell \& Kuparinen (1984) observaron un valor medio de $0.08 \mu \mathrm{m}^{3}$, considerablemente mayor al encontrado por Lee \& Fuhrman (1987). En lagos salinos, Birbir \& Sesal (2003) proporcionan tamaños medios semejantes a los encontrados en el presente estudio, con medidas de las formas bacilares comprendidas entre 1.0-2.5 × 2.5-7.5 $\mu \mathrm{m}$ lineales. Una posible explicación al gran tamaño medio de las bacterias de estos sistemas hipersalinos radicaría en la falta de depredadores selectivos para esos tamaños (nanoflagelados de gran tamaño), siguiendo la idea de Simek \& Chrzanowski (1992).

De la comparación de los tres espectros se deduce que, las bacterias de la salina Los Vélez presentaron la distribución más heterogénea (el espectro presenta más picos) de entre los comparados. Un aspecto a destacar de estos espectros es sin duda el hecho de que las bacterias de gran tamaño (por encima de $4 \mu \mathrm{m}^{3}$ ) estén representadas en mayor proporción en los sistemas propiamente hipersalinos (Los Vélez y San Carlos) que en la laguna Honda. Por otra parte, encontramos una mayor semejanza en la forma de las distribuciones a la izquierda de la moda (esto es para las bacterias más pequeñas) que para las que quedan a la derecha de las mismas.

En principio, sería esperable una mayor semejanza entre los espectros de las dos salinas que

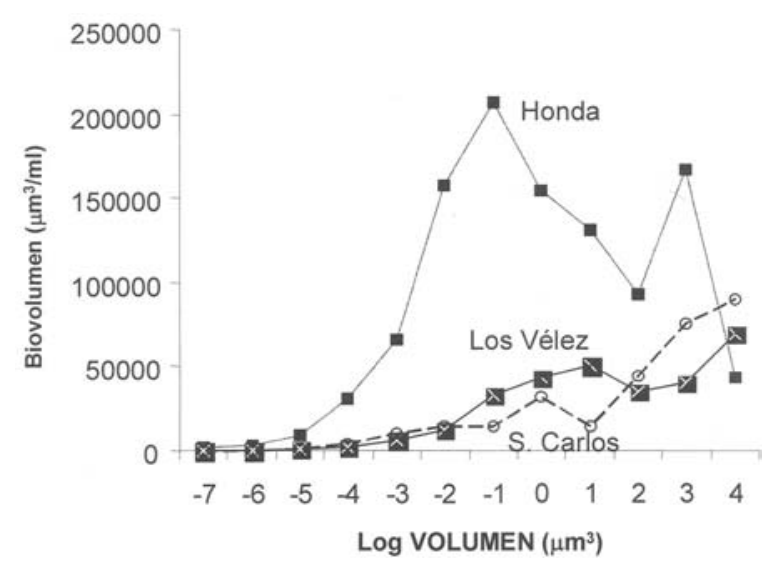

Figura 5. Espectros de biovolumen por clases de tamaño ( $\log _{2}$ de clases) para las distribuciones promediadas en la laguna Honda, Los Vélez y S. Carlos. Biovolume size spectra $\left(\log _{2}\right.$ classes) corresponding to averaged distributions of Honda Lake, Los Vélez, and S. Carlos salterns.

entre éstas y la de la laguna Honda, pero después de observar las distribuciones obtenidas, no se puede llegar a esa conclusión, tal vez debido a la mayor semejanza en TSD entre la laguna Honda y la salina San Carlos.

A partir de estos espectros relativos de abundancia por clases de tamaño se pueden obtener distribuciones de biovolumen por categorías de tamaños (Fig. 5), en cuyo caso, y una vez incluido el fitoplancton, sí que se aprecia claramente la diferencia entre el espectro de biovolumen de la laguna y el de las salinas. Desde el punto de vista del análisis de la forma del espectro de biovolumen se aprecian dos características destacables: (i) la bimodalidad del espectro de la laguna Honda, con máximos en las clases -1 y 3 (correspondientes a un tamaño lineal de 0.98 y 2.48 $\mu \mathrm{m}$ de DEE) y (ii) el carácter creciente del espectro de las dos salinas, de forma que si se ajustase a un modelo lineal se corresponderían con una pendiente positiva del espectro.

Es de destacar que el biovolumen integrado del espectro de tamaños de la laguna Honda es tres veces más alto que la de los otros dos sistemas. Sin embargo, en términos de densidades celulares (Fig. 6) por categorías de tamaños, las diferencias son mucho mayores, 7 veces más en el conjunto de todo el espectro. Una integración del biovolumen de cada uno de los grupos (Tabla 1) permite apreciar el gran predominio del compo- 


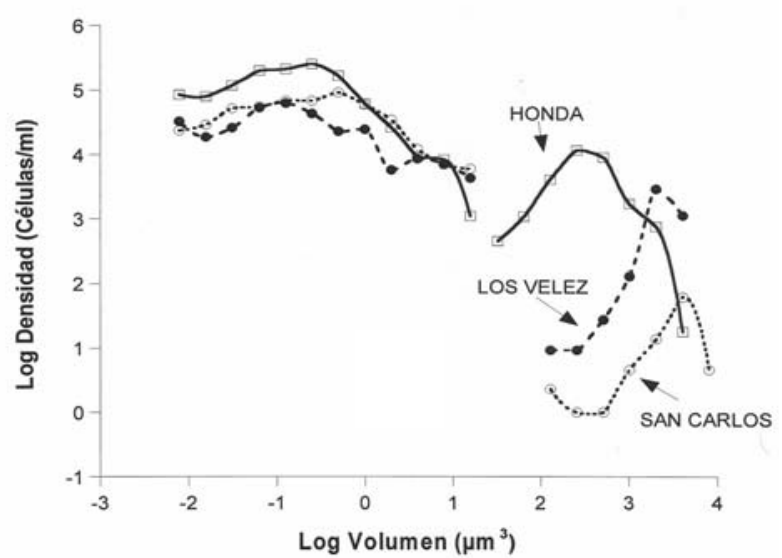

Figura 6. Espectro de abundancias de tamaños de las comunidades bacterianas y fitoplanctónicas en clases logarítmicas $\left(\log _{2}\right)$ para los tres sistemas estudiados. Bacterial and phytoplanktonic size abundance spectrum ( $\log _{2}$ classes) in the three studied ecosystems.

nente fitoplanctónico en la laguna Honda frente a la relativa paridad de los valores de biovolumen de la comunidad bacteriana.

El análisis de la forma del espectro de densidades revela importantes diferencias en la estructura de las comunidades planctónicas analizadas. Dos son los puntos sobre los que se puede llamar la atención: (i) la discontinuidad en la forma del espectro y (ii) el desplazamiento conjunto de las distribuciones de bacterias $\mathrm{y}$ fitoplancton hacia los rangos de mayor tamaño en las comunidades de las salinas. Este rasgo de la estructura del espectro de tamaños, similar al encontrado por Rodríguez et al. (1990) en la laguna de la Caldera y por Havlicek \& Carpenter (2001) para organismos mayores en 11 lagos americanos, parece ser una constante de los sistemas acuáticos de interior. No obstante, se aprecia una clara diferencia entre los sistemas hipersalinos y la laguna salada. Resulta mucho más patente el hueco, la discontinuidad, del espectro de tamaños en los primeros como, por otra parte, sería de esperar en unos ecosistemas de carácter extremo con menores posibilidades de transferencias de materia y energía en la red trófica. Se pone de manifiesto que el análisis de espectros de tamaño puede ser utilizado como un índice de complejidad general del ecosistema y relevante en el diseño de funciones de metas ecológicas (Álvarez-Cobelas \& Rojo, 2000).

\section{AGRADECIMIENTOS}

Este trabajo ha sido realizado gracias al proyecto de investigación REN2001-3441-CO2-01. Agradecemos igualmente a la Consejería de Medio Ambiente de la Junta de Andalucía los permisos concedidos para muestrear en el Paraje Natural de la laguna Honda.

\section{BIBLIOGRAFÍA}

AYADI. H., O. ABID, J. ELLOUMI, A. BOUAIN \& T. SIME-NGANDO. 2004. Structure of the phytoplankton communities in two lagoons of different salinity in the Sfax saltern (Tunisia). J. Plankton Res., 26: 69-679.

ÁLVAREZ-COBELAS, M. \& C. ROJO. 2000. Ecological goal functions and plankton communities in lakes. J. Plankton Res., 22: 729-748.

ANTÓN, J., R. ROSSELLÓ-MORA, F. RODRÍGUEZ-VALERA \& R. AMANN. 2000. Extremely halophylic bacteria in crystallizer ponds from solar salterns. Applied Environmental Microbiology, 66: 3052-3057.

BELL, R. T. \& J. KUPARINEN. 1984. Assessing phytoplankton and bacterioplankton production during early spring in Lake Erken, Sweden. Applied Environmental Microbiology, 48: 1221-1230.

BIRBIR, M. \& C. SESAL. 2003. Extremely halophylic bacteria communities in Sereflikochisar salt lake in Turkey. Turkey Journal of Biology, 27: 7-22.

COLE, J. C., M. L. PACE, N. F. CARACO \& G. S. STEINHART. 1993. Bacterial biomass and cell size distributions in lakes: More and larger cells in anoxic waters. Limnol. Oceanogr., 38: 1627-1632.

CUCCI, T. L. \& M. E. SIERACKI. 2001. Effects of mismatched refractive indices in aquatic flow cytometry. Cytometry, 44: 173-178.

DUSSART, B. 1977. Encyclopedie de l'ecologie, le present en question. Larousse, Paris, pp. 66-78.

GAST, V. \& K. GOCKE. 1988. Vertical distribution of number, biomass and size-class spectrum of bacteria in relation to oxic/anoxic conditions in 
the central Baltic Sea. Marine Ecology Progress Series, 45: 179-186.

GUERRERO, F. \& M. C. CASTRO. 1997. Chlorophyll-a of size-fractionated phytoplankton at a temporary hypersaline lake. International Journal of Salt Lake Research, 5: 253-260.

HAMMER, U. T. 1978. The saline lakes of Saskatchewan. III. Chemical characterization. Int. Revue ges. Hydrobiol., 63: 311-335.

HAVLICEK T. D. \& S. R. CARPENTER. 2001. Pelagic species size distributions in lakes: Are they discontinuous? Limnol. Oceanogr., 46: 1021-1033.

JIMÉNEZ-GÓMEZ, F., B. BAUTISTA \& V. RODRÍGUEZ. 1994. Trophic interactions in the microbial food web at a coastal station in the Alboran Sea (Western Mediterranean) in winter. (II). Size selective flagellate feeding on bacteria and its implication on the microbial loop size-structure. Scientia Marina, 58: 153-159.

LEE, S. \& J. A. FUHRMAN. 1987. Relationships between biovolume and biomass of naturally derived marine bacteriplankton. Applied Environmental Microbiology, 53: 1298-1303.

LI, W. K. W. 1994. Phytoplankton biomass and chlorophyll concentration across the North Atlantic. In: The size structure and metabolism of the pelagic ecosystem. J. Rodríguez y W. K. W Li (eds.). Scientia Marina, 58 (1-2): 67-79. Barcelona.

MARGALEF, R. 1968. Perspectives in Ecologycal Theory. Chicago. University of Chicago Press. 111.

MARGALEF, R. 1983. Limnología. Omega. Barcelona. 1010.

PLATT, T. 1985. Structure of the marine ecosystems: Its allometric basis. In: Ecosystems Theory for Biological Oceanography. R. E. Ulanowicz y T. Platt (eds): Can. Bul. Fish. Aquat. Sci., 213: 55-64.

PLATT, T. 1989. Flow cytometry in Oceanography. In: Cytometry in Aquatic Sciences. C. M. Yentsch y P. K. Horan (eds.). Cytometry, 10: 500.

PLATT, T. \& K. L. DENMAN. 1978. The structure of the pelagic marine ecosystems. Rapp. P.-V. Réun. Cons. Int. Explor. Mer, 173: 60-65.

PORTER K. G. \& Y. S. FEIG. 1980. The use of DAPI for identifying and counting aquatic microflora. Limnol. Oceanogr., 25(5): 943-948.

REUL, A., J. M. VARGAS, F. JIMÉNEZ-GÓMEZ, F. ECHEVARRÍA, J. GARCÍA-LAFUENTE \& J. RODRÍGUEZ. 2002. Exchange of planktonic biomass through the Strait of Gibraltar in late summer conditions. Deep-Sea Research II, 49: 4131-4144.

RODRÍGUEZ, J. \& W. K. W. LI (eds.). 1994. The size structure and metabolism of the pelagic ecosystem. Scientia Marina, 58 (1-2). 167 pp.

RODRÍGUEZ, J., F. ECHEVARRÍA \& F. JIMÉNEZGÓMEZ. 1990. Physiological and ecological scalings of body size in an oligotrophic, high mountain lake (La Caldera, Sierra Nevada, Spain). $J$. Plankton Res., 12: 593-599.

RODRÍGUEZ, J. \& M. M. MULLIN. 1986. Relationship between biomass and body weight of plankton in a steady state oceanic ecosystem. Limnol. Oceanogr., 31: 361-370.

RODRÍGUEZ J., J. M. BLANCO, F. JIMÉNEZGÓMEZ, F. ECHEVARRÍA, J. GIL, V. RODRÍGUEZ, J. RUIZ, B. BAUTISTA \& F. GUERRERO. 1998. Patterns in the size structure of the phytoplankton community in the deep fluorescence maximun of the Alboran Sea (southwestern Mediterranean). Deep-Sea Research I, 45: 1577-1593.

SHELDON, R. W., A. PRAKASH \& W. H. SUTCLIFFE, Jr. 1972. The size distribution of particles in the ocean. Limnol. Oceanogr., 17: 327-340.

SIERACKI, M. E., P. JOHNSON \& J. M. C. N. SIEBURTH. 1985. Detection, enumeration and sizing of planktonic bacteria by image-analyzed epifluorescence microscopy. Applied and Environmental Microbiology, 49: 799-810.

SIMEK, K. \& T. M. CHRZANOWSKI. 1992. Direct and indirect evidence of size-selective grazing on pelagic bacteria by freshwater nanoflagellates. Applied Environmental Microbiology, 58: 3715-3720.

SOROKIN, Y. I., 1999. Aquatic Microbial Ecology: a text book for students in environmental sciences. Leiden. Backhuys Publishers. 248 pp.

SPRULES, W. G. 1988. Effects of trophic interactions on the shape of pelagic size spectra. Verh. Internat. Verein. Limnol. 23: 234-240.

UNESCO. 1994. Protocols for the Joint Global Ocean Flux Study (JGOFS) Core Measurements. SCOR -IOC-UNESCO Manuals and Guides. 29. 178 pp.

WETZEL, R. G. \& M. SONDERGAARD. 1998. Role of submerged macrophytes for the microbial community and dynamics of dissolved organic carbon in aquatic ecosystems. In: The structuring role of submerged macrophytes in lakes. E. Jeppesen, M. Sondergaard y K. Christoffersen (eds.): 133148. Springer-Verlag, Nueva York. 